(192)

\title{
A Comparative Morphological and Anatomical Study of two Memecylon Species: Memecylon umbellatum Burm. f. and Memecylon angustifolium Wight. (Melastomataceae) in Sri Lanka
}

\author{
Karunarathne T.M.S.D. ${ }^{1 *}$, Kariyawasam I.U. ${ }^{1}$, Padumadasa C. ${ }^{2}$ \\ ${ }^{1}$ Department of Botany, University of Sri Jayewardenepura, Sri Lanka \\ ${ }^{2}$ Department of Chemistry, University of Sri Jayewardenepura, Sri Lanka \\ *sakurakarunarathna@gmail.com
}

\begin{abstract}
Memecylon L. is a paleotropical genus with approximately 350 species. It comprises small understory trees or woody shrubs distributed throughout the dry, wet and montane zones in Sri Lanka. According to the Revised Flora of Ceylon, the genus Memecylon (commonly known as "Kora Kaha") comprises 32 different species and among them 28 species are endemic to the island. Memecylon species have a great importance in traditional medicinal practices in Sri Lanka and India. The main objective of this preliminary study is to investigate the comparative morphology and anatomy of the two species Memecylon umbellatum and $M$. angustifolium. Plant materials were collected from the nursery of the Bandaranaike Memorial Ayurvedic Research Institute, Nawinna, grown at the same environmental conditions. Unique vegetative and reproductive morphological characters which can be used to distinguish the two taxa were recorded. Free-hand sectioning, microtomy, leaf vein clearing, light microscopy and powder microscopy were employed for a thorough morphoanatomical investigation. Anatomical characters which are not reported in the local flora treatments earlier, such as stomatal arrangements, foliar sclereids, and wood anatomy were recorded. Transverse sections of mature leaves and powder microscopy showed the presence of druse crystals in both species. Different types of foliar sclereids present in the leaf mesophyll, xylem arrangement in the leaf midrib, xylem vessel thickening patterns, seriation types of the ray parenchyma and the pattern of xylem parenchyma arrangement in the wood were used to separate the two species. This project is the first comprehensive morphological study to investigate the microanatomy of $M$. angustifolium leaves. Variations in morphology and anatomy of the two species combined with a comparative phytochemical study with a better taxon sampling at different ecological zones of the country to identify any cryptic taxa or morphotypes present in this group is recommended for further studies.
\end{abstract}

Keywords: Memecylon umbellatum, Memecylon angustifolium, Melastomataceae, Morphology, Anatomy

Proceedings of the $22^{\text {nd }}$ International Forestry and Environment Symposium 2017 of the Department of Forestry and Environmental Science, University of Sri Jayewardenepura, Sri Lanka 